\title{
Electrooxidation of Formaldehyde on Silver/Ordered Mesoporous Carbon Composite Electrode in Alkaline Solutions
}

\author{
Ling-Bin Kong, Ru-Tao Wang, Xiao-Wei Wang, Zhen-Sheng Yang, Yong-Chun Luo, and Long Kang
}

\begin{abstract}
Metal nanocatalysts, as the anodic materials, have become increasingly important in fuel cells, due to their unique physical and chemical properties. Here, the porous silica was employed as a hard template to prepare the ordered mesoporous carbon (CMK-3). The as-prepared CMK-3 has a large surface area of $877 \mathrm{~m}^{2} / \mathrm{g}$ and the hierarchical porous structure with the pore size distribution centered at $3.7 \mathrm{~nm}$. The CMK-3 supported silver nanocatalysts have been prepared through the wet chemical reduction by using the reduction of formaldehyde. The electrochemical properties of the Ag/CMK-3 nanocatalysts for formaldehyde oxidation are studied by cyclic voltammerry (CV) and chronoamperometric curves (i-t) in alkaline aqueous solutions. The results show that the peak current density (CV) of the $\mathrm{Ag} / \mathrm{CMK}-3$ electrode is 112 $\mathrm{mA} / \mathrm{cm}^{2}$, above 2 times higher than that of $\mathrm{Ag} / \mathrm{XC}-72$ at the same Ag loading $\left(14.15 \mu \mathrm{g} / \mathrm{cm}^{2}\right)$. Furthermore, i-t curves demonstrate that the $\mathrm{Ag} / \mathrm{CMK}-3$ nanocatalysts are efficient and stable electrocatalysts for anodic oxidation of formaldehyde in alkaline solutions. Therefore, $\mathrm{Ag} / \mathrm{CMK}-3$ nanocatalysts with the improved electrocatalytic activity suggest their application potential towards fuel cells and sensors.
\end{abstract}

Index Terms-Nan catalysts; Ag nanoparticles; ordered mesoporous carbon; formaldehyde electro oxidation.

\section{INTRODUCTION}

It's controversial that the formaldehyde is a promising fuel in fuel cells because of the possible relationship between formaldehyde exposure and cancer [1]. Formaldehyde is also one of the initial products of methanol oxidation which has its fundamental and technological importance in industrial catalytic processes [2]. The electrooxidation mechanism of formaldehyde has been widely investigated on Pt [3], Pd [4], and $\mathrm{Rh}[5]$ electrodes which are mostly in connection with fuel cells and sensors. Whereas, these anodic materials are the noble metal with their scarcity, and can't lower the commercial cost. New metal nanocatalysts with high electrochemical catalytic properties and low commercial cost can be explored by rational designing of their compositions and structures. As been well known, silver is more abundant in nature and less expensive than platinum and palladium, as

Manuscript received May 9, 2011; revised June 2, 2011

This work was supported in part by the the National Natural Science Foundation of China (No. 50602020), the Natural Science Foundation of Gansu Province (No. 0803RJZA002) and the Program for Outstanding Young Teachers in Lanzhou University of Technology (Q200803).

Ling-Bin Kong is with State Key Laboratory of Gansu Advanced Non-ferrous Metal Materials, Lanzhou University of Technology, Lanzhou 730050, P. R. China (e-mail: konglb@ lut.cn).

Long Kang is with School of Materials Science and Engineering, Lanzhou University of Technology, Lanzhou 730050, P. R. China (e-mail: kongl@lut.cn). a result, cost associated issues is one of the main driving force behind the increasing interest in silver as the anodic materials in fuel cells. Moreover, the real and most important attraction for Ag-based electro catalysts is originated by the fact that they can be highly active in the electro oxidation of formaldehyde in alkaline environment, where other non-noble metals are not sufficiently active and stable for electrochemical applications. Recently, Gang and Lu [6] reported that the Ag nimrods had the satisfying electro oxidation property for formaldehyde in alkaline solution.

In general, the catalytic properties of metal are dependent upon the size, composition, structure, as well as the support materials [7]-[9]. Especially, the support materials [10]-[12], such as MCM-n, SBA-n, CMK-n, can disperse the metal clusters homogeneously and stably owing to their desirable hosting structure. The ordered Mesoporous carbon (CMK-3) is the promising material for its numerous applications because of its large specific surface areas, high chemical inertness, good conductivity, and mechanical stability [13]. It is an ideal host for synthesis of nanocatalysts. Ryoo and co-worker investigated oxygen reduction using Pt-loaded mesoporous carbonized SBA-15, and observed a significant increase in reduction current, compared to $\mathrm{Pt}$ loaded in conventional carbon (such as carbon black, charcoal and activated carbon fibers), using a rotating electrode and Nations as the binding incomer [14]. Therefore, the higher electro oxidation properties for formaldehyde of nana-sized $\mathrm{Ag}$, combined with the desirable hosting structure of CMK-3 mentioned above, strongly suggest that the $\mathrm{Ag} / \mathrm{CMK}-3$ nanocatalysts have the higher activity for formaldehyde electro oxidation as the anodic materials.

In this paper, chemically synthesized $\mathrm{Ag} / \mathrm{CMK}-3$ nanocatalysts are prepared by reducing silver nitrate with the formaldehyde in aqueous CMK-3 solution. The structure and nature of the resulting $\mathrm{Ag} / \mathrm{CMK}-3$ nanocatalysts are characterized by transmission microscopy (TEM) and X-ray diffraction (XRD). The catalytic properties of the Ag/CMK-3 nanocatalysts for formaldehyde electro oxidation have been investigated in alkaline environment. The results demonstrate that the as-prepared $\mathrm{Ag} / \mathrm{CMK}-3$ nanocatalysts exhibit excellent electro catalytic activity and long-term stability for formaldehyde electro oxidation, implying its potential to substitute for noble metal catalysts in fuel cells and sensors.

\section{EXPERIMENTAL}

\section{A. Synthesis of CMK-3}

All reagents were of analytical grade. The CMK-3 was synthesized, following the method described by Ryoo and 
co-workers [15]. $1 \mathrm{~g}$ of SBA-15 was added to a solution obtained by dissolving $1 \mathrm{~g}$ of sucrose and $0.147 \mathrm{~g}$ of $\mathrm{H}_{2} \mathrm{SO} 4$ in $5 \mathrm{~g}$ of $\mathrm{H}_{2} \mathrm{O}$. The SBA-15 was synthesized, following the method reported by Zhao et al [16]. The mixture was placed in a drying oven for $6 \mathrm{~h}$ at $373 \mathrm{~K}$, and subsequently the oven temperature was increased to $433 \mathrm{~K}$ and maintained for $6 \mathrm{~h}$. The silica sample, containing partially polymerized and carbonized sucrose at the present step, was treated again at 373 and $433 \mathrm{~K}$ using the same drying oven after the addition of $0.8 \mathrm{~g}$ of sucrose, $0.09 \mathrm{~g}$ of $\mathrm{H}_{2} \mathrm{SO}_{4}$ and $5 \mathrm{~g}$ of $\mathrm{H}_{2} \mathrm{O}$. The carbonization was completed by pyrolysis with heating to typically $1173 \mathrm{~K}$ under vacuum. The carbon-silica composite obtained after paralysis was washed with $5 \mathrm{wt} \%$ hydrofluoric acid at room temperature, to remove the silica template. The template-free carbon product thus obtained was filtered, washed with ethanol, and dried at $373 \mathrm{~K}$.

\section{B. Synthesis of $\mathrm{Ag} / \mathrm{CMK}-3$ nanocomposite}

The CMK-3 supported Ag catalysts were synthesized via a wet chemical reduction method [17]. Briefly, $50 \mathrm{mg}$ of pristine CMK-3 and $19.7 \mathrm{mg} \mathrm{AgNO}_{3}$ were added into $10 \mathrm{ml}$ distilled water, and then were ultra-sonicated about $30 \mathrm{~min}$ to disperse them uniformly. Then $10 \mathrm{ml}$ formaldehyde as the reduction agent solved in $10 \mathrm{ml}$ water was slowly drop wised into the suspension solution. The $\mathrm{pH}$ value of the mixture was adjusted to 11 by adding the aqueous $1 \mathrm{M} \mathrm{NaOH}$ solution under vigorous stirring. Finally, the mixture was refluxed at $85{ }^{\circ} \mathrm{C}$ for $2 \mathrm{~h}$ in a heating mantle, after it was agitated vigorous under room temperature for $4 \mathrm{~h}$. The black solid slurries were filtrated, washed and dried at $90{ }^{\circ} \mathrm{C}$ for more than $10 \mathrm{~h}$ in a vacuum oven, and then, the $\mathrm{Ag} / \mathrm{CMK}-3$ nanocatalysts were obtained. For comparison, $\mathrm{Ag}$ nanocatalyst supported on Vulcan XC-72R carbon black (Cabot, USA, BET: $213 \mathrm{~cm}^{2} / \mathrm{g}$ ), denoted as Ag/XC-72, was also prepared under the same preparation conditions.

\section{Preparation of electrodes and electrochemical measurements}

Electrochemical measurements were performed using an electrochemical working station (CHI660C, Shanghai Chinua, and China) and a standard three-electrode cell at room temperature (about $22{ }^{\circ} \mathrm{C}$ ). A commercial saturated calomel electrode (SCE) and a platinum foil were used as reference electrode and counter electrode respectively. The glassy carbon electrode (GC, $3 \mathrm{~mm}$ in diameter, geometric area: $0.07 \mathrm{~cm}^{2}$ ) was polished mechanically to be a mirror by successively using the alumina powder of size $30 \mathrm{~nm}$, followed by cleaning in an ultrasonic bath and dring in an oven at $313 \mathrm{~K} .1 \mathrm{mg}$ of catalysts and then were dispersed ultrasonically in $1 \mathrm{~mL}$ of an ethanol solution of $5 \mathrm{wt} \%$ Nafion to obtain a homogeneous black suspension. Then, $5 \mu \mathrm{l}$ of the suspensions were dropped onto the GC electrode surface using a micropipette. The coating was then dried at room temperature in air. To measure the catalytic activity of Ag/CMK-3 nanocatalysts towards electro oxidation of formaldehyde oxidation, cyclic voltammeters (CV) and current-time (i-t) curves methods were employed and performed at a sweep rate of 50 and $100 \mathrm{mV} / \mathrm{s}$.

\section{Sample characterization}

The samples were characterized by using a Rigaku D/Max-2400 X-ray diffract meter (XRD) with a $\mathrm{Cu} \mathrm{K} \alpha$ radiation resource to determine the crystalline structure. Transmission electron microscope (TEM) images were obtained with a JEOL JEM-2010 microscope (Japan) operated at $200 \mathrm{KV}$ and equipped with an energy-dispersive spectrometer (EDS). Nitrogen adsorption-desorption data was obtained by using an AASP 2010M (Micromeritics, US). The surface area of CMK-3 was calculated using the Brinier Emmett Teller (BET) equation. Pore size distributions of CMK-3 were calculated by the Barrett-Joyner-Helena (BJH) method using the desorption branch of the isotherm.

\section{RESULTS AND DISCUSSION}

Fig. 1 shows the $\mathrm{N}_{2}$ adsorption-desorption isotherm of the synthesized CMK-3 materials. In terms of shape, the isotherm for CMK-3 can be classified as type IV according to the IUPAC. A distinct hysteresis loop can be observed in the range of ca. $0.4-1.0 \mathrm{P} / \mathrm{P}_{0}$, indicating the presence of mesopores. The as-prepared CMK-3 have a large surface area of $877 \mathrm{~m}^{2} / \mathrm{g}$ and the hierarchical porous structure with the pore size distribution centered at $3.7 \mathrm{~nm}$, as measured by the Brunauer-Emmett-Teller (BET) measurements. The large surface area of CMK-3 indicates that the CMK-3 is an ideal host for synthesis of nanocatalysts.

Fig. 2 shows the XRD patterns of the two samples of $\mathrm{Ag} / \mathrm{CMK}-3$ and $\mathrm{Ag} / \mathrm{XC}-72$ nanocatalysts. The diffraction
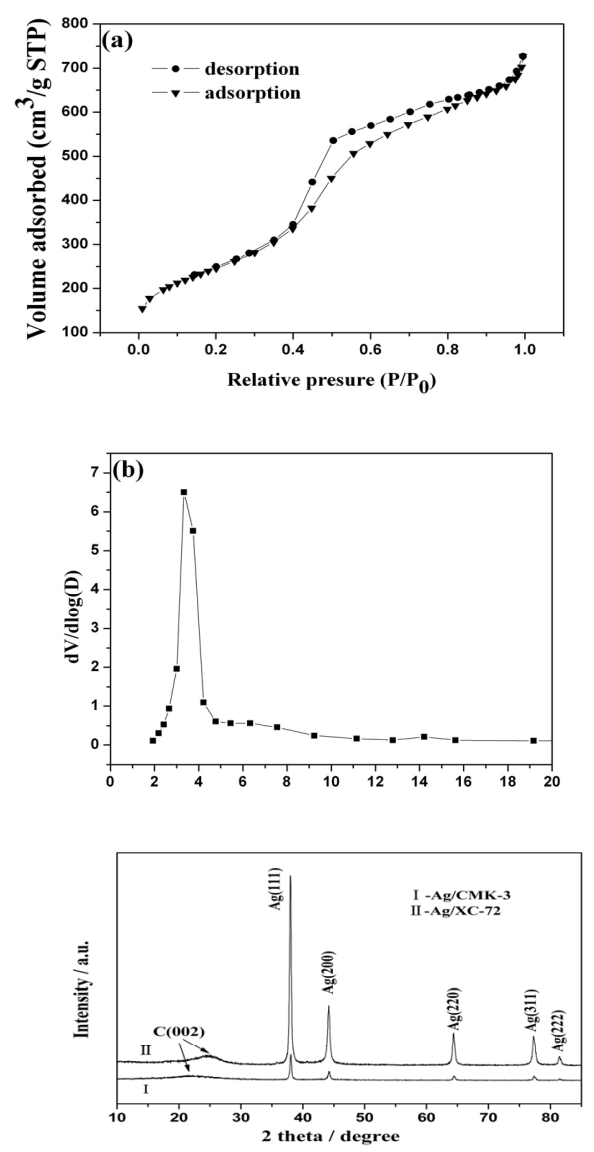

Fig. 2. XRD pattern of the $\mathrm{Ag} / \mathrm{CMK}-3$ and $\mathrm{Ag} / \mathrm{XC}-72$ samples nanocatalysts.

Peaks of Ag nanoparticles corresponding to different planes can be observed from the pattern obviously. The peaks can be assigned to the Ag face-centered cubic (fcc) phase, namely the planes (111), (200), (220), (311), (222), indicating the successful fabrication of $\mathrm{Ag}$ nanopaticles onto 
the CMK-3 and XC-72. No diffraction peaks could be attributed to silver oxides in the XRD. The X-ray diffraction peak at $22^{\circ}$ and $24.1^{\circ}$ can be attributed to the hexagonal graphite structure (002) [18].

The typical morphology of $\mathrm{Ag} / \mathrm{CMK}-3$ and $\mathrm{Ag} / \mathrm{XC}-72$ nanocatalysts was characterized by transmission electron microscopy (TEM). The ordered 2-D mesoporous texture of the Ag/CMK-3 can be seen in Fig. 3(a) and (b). In our case $\mathrm{Ag}$ nanoparticles with a broad size distribution ranging from 80 to $200 \mathrm{~nm}$ are homogeneous dispersed on the surface of CMK-3, and some large aggregates of metal Ag in shape could also be found on the surface of CMK-3, due to the Ag nanoparticles with the characteristic of easy aggregation are not generally more stable than $\mathrm{Au}, \mathrm{Pt}$ nanoparticles [19]. The chemical nature of these $\mathrm{Ag} / \mathrm{CMK}-3$ nanocomposites can be detected by ED's measurements (Fig. 3(c)). A typical EDS spectrum for Ag nanoparticle modified CMK-3 supported by peaks, arising from the Ag nanoparticles, CMK-3 and copper foil substrate. In addition, ED pattern for the $\mathrm{Ag} / \mathrm{CMK}-3$ nanocatalysts show several bright concentric rings, polycrystalline metal Ag. The morphology of $\mathrm{Ag} / \mathrm{XC}-72$ was shown in fig. 3(d).

A better and direct understanding of the catalytic properties of the resulting Ag catalysts are sought by carrying out electrochemical measurements in $1 \mathrm{M} \mathrm{KOH}$ aqueous solution in the absence and presence of $1 \mathrm{M}$ formaldehyde. The typical behavior for Ag electrode in alkaline medium and a broader discussion of the oxidation-reduction results were discussed elsewhere [20, 21]. In the anodic potential (fig. 4(a) ), current peaks are related to the electro dissolution of $\mathrm{Ag}$ to $\left[\mathrm{Ag}(\mathrm{OH})_{2}\right]^{-}$through adsorption of $\mathrm{OH}^{-}$and the electroformation of multilayer of $\mathrm{Ag}_{2} \mathrm{O}$ and $\mathrm{AgO}$. On the other hand, the more negative cathodic peaks could be attributed to the processes involved in the electro-reduction of $\mathrm{Ag}_{2} \mathrm{O}$ and $\mathrm{AgO}$ to $\mathrm{Ag}$. From the $\mathrm{CV}$ measured in $1 \mathrm{M} \mathrm{KOH}$, it also shows the electrochemical active surfaces of Ag/CMK-3 nanocomposites [6], and Ag/CMK-3 samples exhibit higher oxidation-reduction peak than the $\mathrm{Ag} / \mathrm{XC}-72$ samples, indicating that the $\mathrm{Ag} / \mathrm{CMK}-3$ nanocatalysts have the higher electrode active surface.

The electrooxidation of formaldehyde on metal, such as Pt, $\mathrm{Cu}, \mathrm{Rh}$ et al., has been widely reported [1]-[5]. In aqueous solutiongs, formaldehyde exists mainly in its hydrated form, methylene glycol $\left(\mathrm{H}_{2} \mathrm{C}(\mathrm{OH})_{2}\right)$, and the following electrochemical oxidation maybe occur on Ag surface:

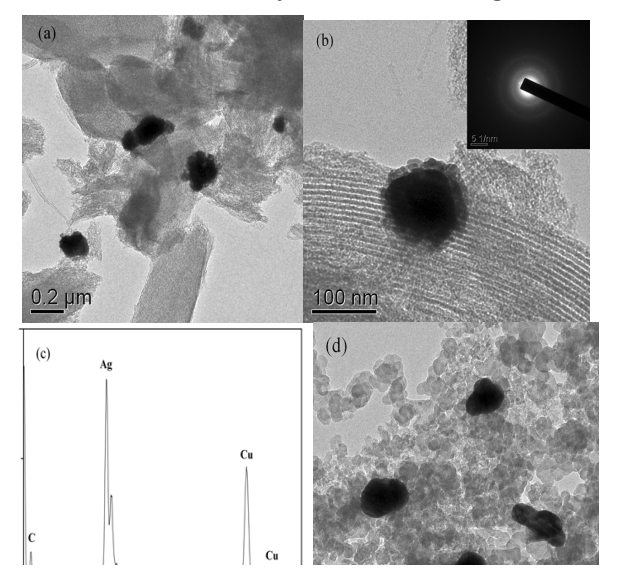

Fig. 3. (a), (b) TEM images of Ag/CMK-3 nanocatalysts; Top-right inset shows the corresponding ED pattern. (c) EDS spectrum of Ag/CMK-3. (d) TEM image of $\mathrm{Ag} / \mathrm{XC}-72$.
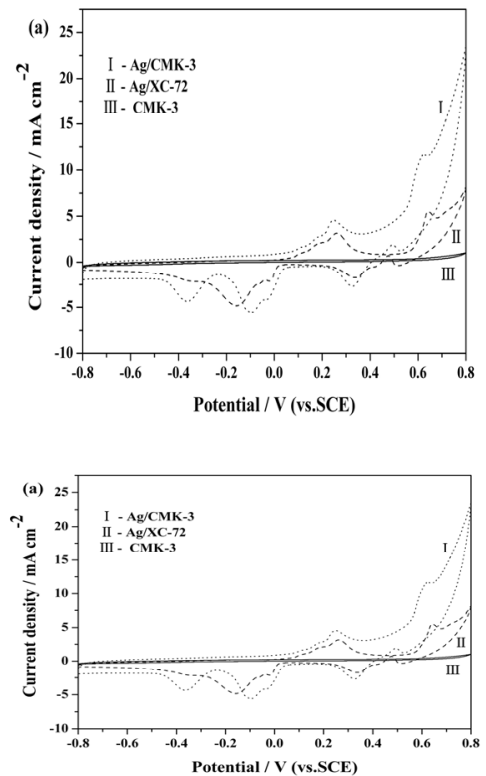

Fig. 4. CV at glassy carbon electrode modified by Ag nanocatalysts (a) in $1 \mathrm{M} \mathrm{KOH}$, (b) in $1 \mathrm{M} \mathrm{KOH}+1 \mathrm{M}$ formaldehyde. Scan rate: $100 \mathrm{mV} / \mathrm{s}$.

$$
\begin{aligned}
& \mathrm{HCHO}+\mathrm{H}_{2} \mathrm{O} \rightarrow \mathrm{H}_{2} \mathrm{C}(\mathrm{OH})_{2} \\
& \mathrm{H}_{2} \mathrm{C}(\mathrm{OH})_{2} \rightarrow \mathrm{CO}_{\text {ads }}+\mathrm{H}_{2} \mathrm{O}+2 \mathrm{H}^{+}+2 \mathrm{e}^{-} \\
& \mathrm{H}_{2} \mathrm{C}(\mathrm{OH})_{2} \rightarrow \mathrm{H}_{2} \mathrm{COO}_{\text {ads }}+2 \mathrm{H}^{+}+2 \mathrm{e}^{-} \\
& \mathrm{CO}_{\text {ads }}+\mathrm{H}_{2} \mathrm{O} \rightarrow \mathrm{CO}_{2}+2 \mathrm{H}^{+}+2 \mathrm{e}^{-} \\
& \mathrm{H}_{2} \mathrm{COO}_{\mathrm{ads}} \rightarrow \mathrm{CO}_{2}+2 \mathrm{H}^{+}+2 \mathrm{e}^{-}
\end{aligned}
$$

Here, $\mathrm{CO}_{\mathrm{ads}}$ and $\mathrm{H}_{2} \mathrm{COO}_{\mathrm{ads}}$ mean the adsorbed species on metal electrode surface. The reaction procedure presented above can show the formaldehyde oxidation behavior at $\mathrm{Ag}$ electrode is the four-electron oxidation process and yields $\mathrm{CO}_{2}$ as the final produce on the basis of parallel pathway involving two adsorbed intermediates $\left(\mathrm{CO}_{\mathrm{ads}}\right.$ and $\left.\mathrm{H}_{2} \mathrm{COO}_{\mathrm{ads}}\right)$. Fig. 4(b) shows the typical cyclic voltammograms of Ag in 1 $\mathrm{M}$ formaldehyde $+1 \mathrm{M} \mathrm{KOH}$ solution. It can be observed that

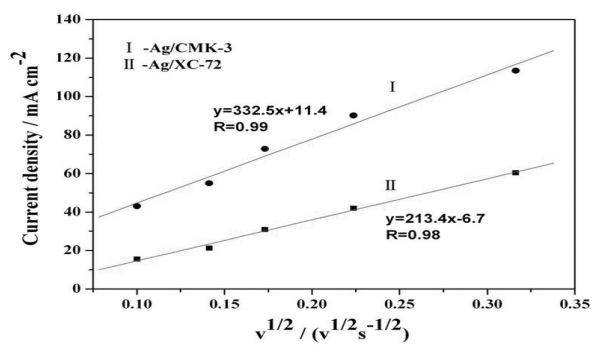

Fig. 5. Dependence of peak current densities on the square root of scan rates of $\mathrm{Ag} / \mathrm{CMK}-3$ and $\mathrm{Ag} / \mathrm{XC}-72$ nanocatalysts measured in $1 \mathrm{M} \mathrm{KOH}+1$ $\mathrm{M}$ formaldehyde solution.

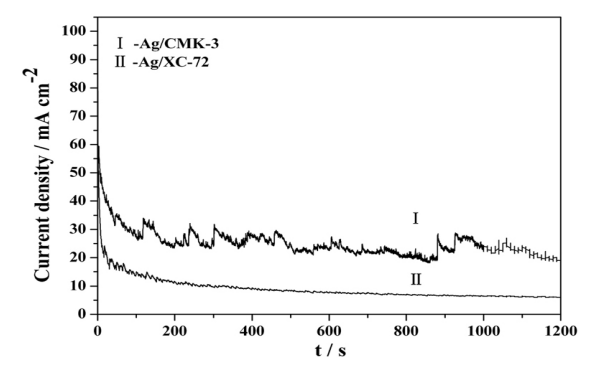

Fig. 6. Current-time curves of formaldehyde electro-oxidation on $\mathrm{Ag} / \mathrm{CMK}-3$ and $\mathrm{Ag} / \mathrm{XC}-72$ nanocatalysts in $1 \mathrm{M} \mathrm{KOH}+1 \mathrm{M}$ formaldehyde solution 
the CMK-3 modified GC electrode appear to be inactive for anodic oxidation of formaldehyde. In the typical curve of $\mathrm{Ag}$ catalysts, the main oxidation peak potentials are located at 0.2 $\mathrm{V}$ and $0.4 \mathrm{~V}$ (vs. SCE), corresponding peak current density is 60.9 and $112 \mathrm{~mA} / \mathrm{cm}^{2}$, respectively. It clearly shows the electrocatalytic activity of $\mathrm{Ag} / \mathrm{CMK}-3$ nanocatalysts is higher than that of $\mathrm{Ag} / \mathrm{XC}-72$ nanocatalysts and also demonstrates the $\mathrm{Ag} / \mathrm{CMK}-3$ nanocatalysts have the higher electrochemical active surfaces. As stated above, it should be mentioned that the large Ag nanoparticles, even exceeding $100 \mathrm{~nm}$, also show the high electrocatalytic activity for formaldehyde electrooxidation. The enhanced electrocatalytical properties can be attributed to the CMK-3 supports with the large surface areas and the highly ordered mesoporous texture which are in favor of dispersing the $\mathrm{Ag}$ nanoparticles homogeneous and providing Ag electrode with high electrocatalytic activity. Moreover, the loadings of $\mathrm{Ag}$ on the XC-72 or CMK-3 coated GC electrode are about $1 \mu \mathrm{g}$, and the corresponding maximum current densities of $\mathrm{Ag}$ were calculated about $4.3 \mathrm{~A} / \mathrm{mg}$ and $7.91 \mathrm{~A} / \mathrm{mg}$, respectively. To best of our knowledge, these results are obviously higher than the reports of $\mathrm{Ag}$ nanorods for formaldehyde electrooxidation [6].

Compared with the relation between the peaks current obtained from $\mathrm{CVs}$ scan and the square root of scan rates, which is shown in Fig. 5, a linear relationship is observed, suggesting that the electrocatalytic oxidation of formaldehyde on $\mathrm{Ag} / \mathrm{CMK}-3$ and and $\mathrm{Ag} / \mathrm{XC}-72$ nanocatalysts is the diffusion-controlled process [22].

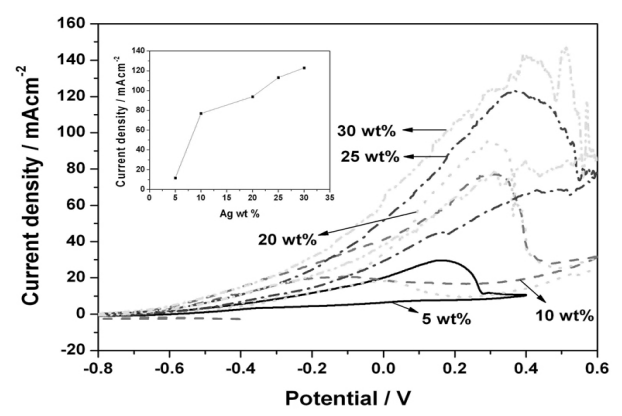

Fig. 7. $\mathrm{CV}$ at glassy carbon electrode modified by $\mathrm{Ag} / \mathrm{CMK}-3$ composites with different Ag loading in $1 \mathrm{M} \mathrm{KOH}+1 \mathrm{M}$ formaldehyde. Scan rate: $50 \mathrm{mV} / \mathrm{s}$. Inset shows dependence of peak current densities on Ag/CMK-3 composites with different Ag loading

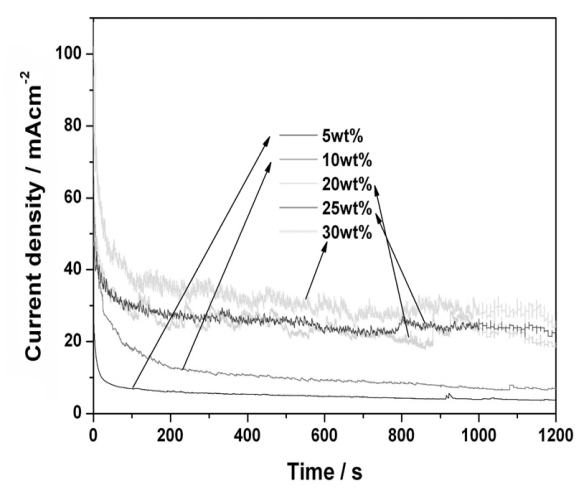

Fig. 8. Current-time curves of formaldehyde electro-oxidation on $\mathrm{Ag} / \mathrm{CMK}-3$ composites with different $\mathrm{Ag}$ loading in $1 \mathrm{M} \mathrm{KOH}+1 \mathrm{M}$ formaldehyde solution.

It can be further discussed the electrocatalytic stability and activity of the catalysts under continuous operating conditions, then long-term chronoamperometric (current-time) experiments are investigated in $1 \mathrm{M}$ formaldehyde and $1 \mathrm{M} \mathrm{KOH}$ aqueous solution. Fig. 6 shows the current-time (i-t) curves of formaldehyde oxidation which are applied at 0.2 and $0.4 \mathrm{~V}$ (vs. SCE), corresponding to the anodic current peak (CV) for $\mathrm{Ag} / \mathrm{XC}-72$ and $\mathrm{Ag} / \mathrm{CMK}-3$ electrodes, respectively. It can be observed that the limiting current densities on $\mathrm{Ag} / \mathrm{CMK}-3$ and $\mathrm{Ag} / \mathrm{XC}-72$ after $1200 \mathrm{~s}$ are 18.8 and $6 \mathrm{~mA} / \mathrm{cm}^{2}$, respectively, indicating a significantly enhanced catalytic activity and stability to formaldehyde electrooxidation of $\mathrm{Ag} / \mathrm{CMK}-3$ nanocatalysts. This result is consistent with that of $\mathrm{CV}$. As the weight percentage of $\mathrm{Ag}$ in $\mathrm{Ag} / \mathrm{CMK}-3$ composite increases, the electrocatalytic activity for formaldehyde oxidation of $\mathrm{Ag} / \mathrm{CMK}-3$ electrode also increases, this can be observed in cyclic voltammograms test (Fig. 7) and long-term chronoamperometric (current-time) experiments (Fig. 8). On the basis of these results, as mentioned above, it strongly suggested that the Ag/CMK-3 nanocatalysts have the higher catalytic activity for the electrooxidation of formaldehyde.

\section{CONCLUSION}

In summary, $\mathrm{Ag} / \mathrm{CMK}-3$ nanocatalysts have been successfully synthesized through the facile wet chemical reduction. The electrocatalytic activity of $\mathrm{Ag} / \mathrm{CMK}-3$ nanocatalysts has been tested for formaldehyde electrooxidation in alkaline media. The results of $\mathrm{CV}$ and i-t curves demonstrate that $\mathrm{Ag} / \mathrm{CMK}-3$ nanocatalysts have the significantly enhanced activity and high stability towards the electrooxidation of formaldehyde. This finding represents a significant step toward the implementation of individual $\mathrm{Ag} / \mathrm{CMK}-3$ nanocatalysts as anodic materials in fuel cells and sensors.

\section{ACKNOWLEDGMENT}

This work was supported by the National Natural Science Foundation of China (No. 50602020), the Natural Science Foundation of Gansu Province (No. 0803RJZA002) and the Program for Outstanding Young Teachers in Lanzhou University of Technology (Q200803).

\section{REFERENCES}

[1] M. Hasanzadeh, B. Khalizadeh, N. Shadjou, G. Karim-Nezhad, L. Saghatforoush, I. Kazeman, M.H. Abnosi, "A New Kinetic-Mechanistic Approach to Elucidate Formaldehyde Electrooxidation on Copper Electrode," Electroanalysis, vol. 22, pp. 168-176, Nov. 2009.

[2] E.A. Batista, T. Iwasita, "Adsorbed Intermediates of Formaldehyde Oxidation and Their Role in the Reaction Mechanism," Langmuir, vol. 22, pp. 7912-7916, Jul. 2006.

[3] Z. Wang, Z.Z. Zhu, J. Shi, H.L. Li, "Electrocatalytic oxidation of formaldehyde on platinum well-dispersed into single-wall carbon nanotube/polyaniline composite film," Appl. Surf. Sci, vol. 253, pp. 8811-8817, Sept. 2007.

[4] G.Y. Cao, D.J. Guo. H.L. Li, "Electrocatalytic oxidation of formaldehyde on palladium nanoparticles supported on multi-walled carbon nanotubes," J. Power Sources, vol. 162, pp. 1094-1098, Nov. 2006.

[5] B.R. Sathe, D.B. Shinde, V.K. Pillai, "Preparation and Characterization of Rhodium Nanostructures through the Evolution of Microgalvanic Cells and Their Enhanced Electrocatalytic Activity for Formaldehyde Oxidation,” J. Phys. Chem. C., vol. 113, pp: 9616-9622, May. 2009. 
[6] J.L. Geng, Y.P. Bi, G.X. Lu, "Morphology-dependent activity of silver nanostructures towards the electro-oxidation of formaldehyde," Electrochem. Commun., vol. 11, pp: 1255-1258, Jun. 2009.

[7] P. Ferrin, M. Mavrikakis, "Structure Sensitivity of Methanol Electrooxidation on Transition Metals," J. Am. Chem. Soc., vol. 131, pp: 14381-14389, Sept. 2009.

[8] C. Bianchini, P.K. Shen. "Palladium-Based Electrocatalysts for Alcohol Oxidation in Half Cells and in Direct Alcohol Fuel Cells" Chem. Rev., vol. 109, pp: 4183-4206, Jul. 2009.

[9] I. Lee, F. Delbecq, R. Morales, M.A. Albiter, F. Zaera. "Tuning selectivity in catalysis by controlling particle shape," Nature Mater, vol 8, pp: 132-138, Jan. 2009.

[10] A. Taguchi, F. Schüth," Ordered mesoporous materials in catalysis" Microporous Mesoporous Mater, vol. 77, pp: 1-45, Jan 2005.

[11] H. Chang, S.H. Joo, C. Pak, "Synthesis and characterization of mesoporous carbon for fuel cell applications," J. Mater. Chem., vol. 17, pp: 3078-3088, May. 2007

[12] J.L. Shi, Z.L. Hua, L.X. Zhang, "Nanocomposites from ordered mesoporous materials," J. Mater. Chem., vol. 14, pp: 795-806, Jan 2004.

[13] R. Ryoo, S.H. Joo, M. Kruk, M. Jaroniec, "Ordered Mesoporous Carbons,"Adv. Mater., vol. 13, pp: 677-681, May. 2001.

[14] S. H. Joo, S. J. Choi, I. Oh, J. Kwak, Z. Liu, O. Terasaki, R. Ryoo, "Ordered nanoporous arrays of carbon supporting high dispersions of platinum nanoparticles," Nature, vol. 412, pp: 169-172, July 2001.

[15] H.J. Shin, R. Ryoo, M. Kruk, M. Jaroniec, "Modification of SBA-15 pore connectivity by high-temperature calcination investigated by carbon inverse replication," Chem. Commun., pp. 349-350, Feb. 2001

[16] D.Y. Zhao, J.L. Feng, Q.S. Huo, N. Melosh, G.H. Fredrickson, B.F. Chmelka, G.D. Stucky, "Triblock Copolymer Syntheses of Mesoporous Silica with Periodic 50 to 300 Angstrom Pores," Science, vol. 279, pp: 548-552, Jan. 1998.

[17] J.E. Huang, D.J. Guo, Y.G. Yao, H.L. Li, "High dispersion and electrocatalytic properties of platinum nanoparticles on surface-oxidized single-walled carbon nanotubes," J. Electroanal. Chem., vol 577, pp: 93-97, Mar. 2005.

[18] E.N. Coker, W.A. Steen, J.T, Miller, A.J. Kropf, J.E. Miller, "Nanostructured $\mathrm{Pt} / \mathrm{C}$ electrocatalysts with high platinum dispersions through zeolite-templating," Microporous Mesoporous Mater, vol. 101, pp. 440-444, Apr 2007.
[19] S.Z. Zhang, W.H. Ni, X.S. Kou, M.H. Yeung, L.D. Sun, J.F. Wang, C.H. Yan, "Formation of Gold and Silver Nanoparticle Arrays and Thin Shells on Mesostructured Silica Nanofibers," Adv. Funct. Mater., vol. 17, pp: 3258-3266, Sept. 2007.

[20] S.L. Chen, B.L. Wu, C.S. Cha, "Application of time-resolved EQCM to the study of the mechanism of silver(I) oxide formation on a polycrystalline silver electrode in alkaline solution", J. Electroanal. Chem., vol.416, pp: 53-59, Apr. 1996.

[21] L. Majari Kasmaee, F. Gobal, "A preliminary study of the electro-oxidation of l-ascorbic acid on polycrystalline silver in alkaline solution,” J. Power Sources., vol. 195, pp: 165-169, Jan. 2010.

[22] Z.P. Sun, X.G. Zhang, H. Tong, Y.Y. Liang, H.L. Li, "Sulfonation of ordered mesoporous carbon supported Pd catalysts for formic acid electrooxidation," J. Colloid Interface Sci., vol. 337, pp: 614-618, May. 2009.

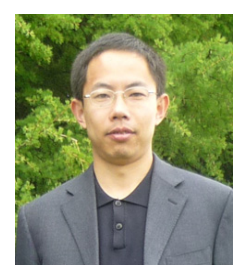

Ling-Bin Kong, is an associate professor in the School of Materials Science and Engineering, Lanzhou University of Technology at Lanzhou, China. He received his Ph.D. (2004) from Lanzhou University, in physical chemistry, under the supervision of Prof. Hu-Lin Li. His current research interest is mainly focused on the design and synthesis of metal oxides, metal nanoparticles, and mesoporous carbon materials, as well as their applications for energy conversion and storage.

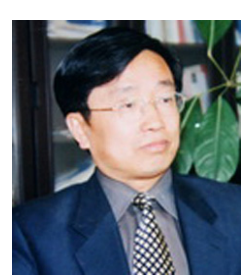

Long Kang, is a professor in the School of Materials Science and Engineering, Lanzhou University of Technology at Lanzhou, China. He received his M.Sc. (1984) from Xi'an Jiaotong University. He was twice as the visiting scholar at Tohoku University and Japan Institute of Department of Metal Materials. His current research interest is mainly focused on the material physics and chemistry, designing, assembling and structures of rare earths functional materials. 